Document downloaded from:

http://hdl.handle.net/10251/77668

This paper must be cited as:

Cubero García, S.; Aleixos Borrás, MN.; Albert Gil, FE.; Torregrosa, A.; Ortiz Sánchez, MC.; García Navarrete, OL.; Blasco Ivars, J. (2014). Optimised computer vision system for automatic pre-grading of citrus fruit in the field using a mobile platform. Precision Agriculture. 15(1):80-94. doi:10.1007/s11119-013-9324-7.

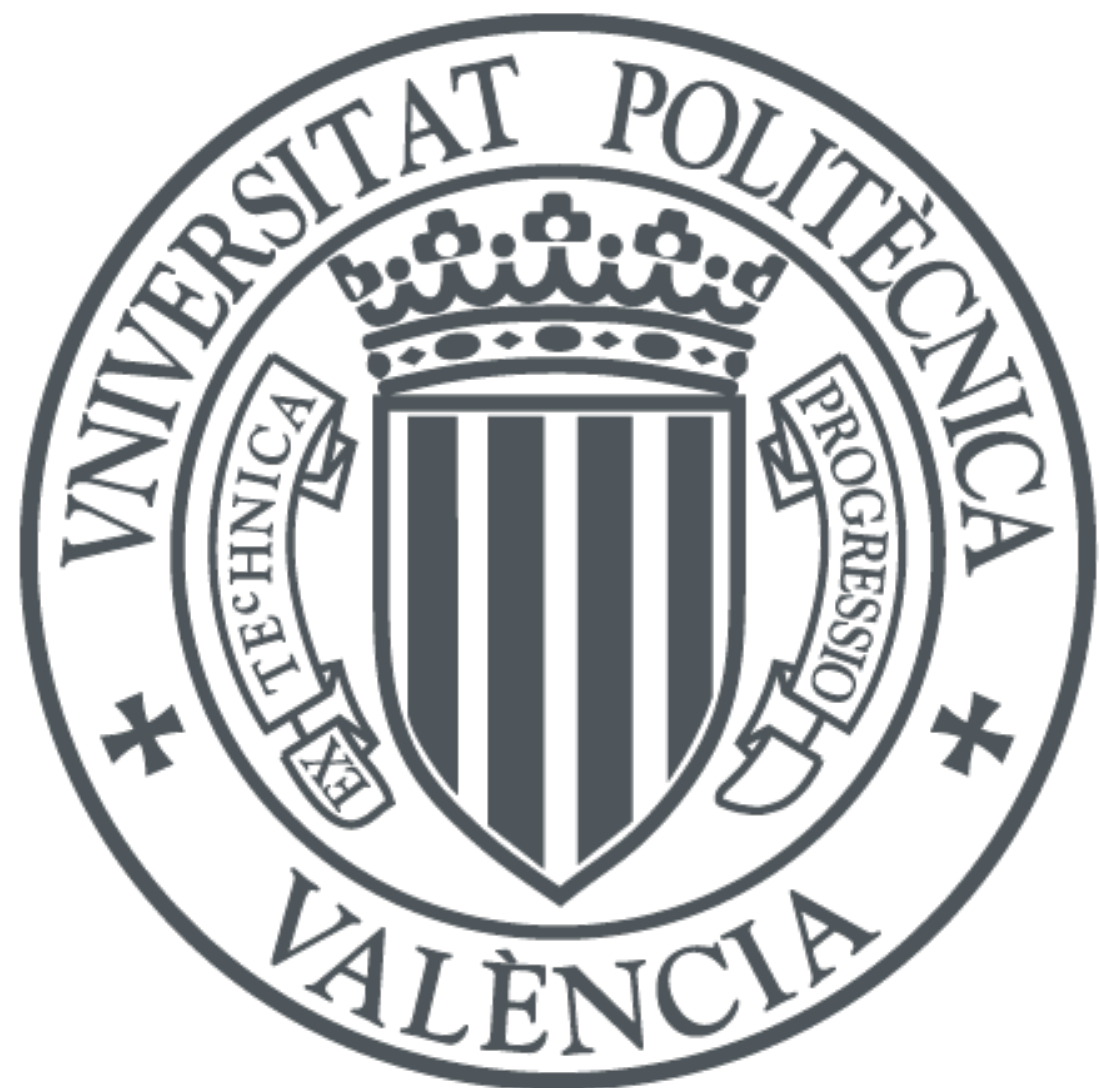

The final publication is available at

http://dx.doi. org/10.1007/s11119-013-9324-7

Copyright Springer Verlag

Additional Information 


\title{
Optimised computer vision system for automatic pre-grading of citrus fruit in the field using a mobile platform
}

\author{
S. Cubero ${ }^{1}$, N. Aleixos ${ }^{2}$, F. Albert ${ }^{2}$, A. Torregrosa ${ }^{3}$, C. Ortiz ${ }^{3}$, O. García-Navarrete ${ }^{1,4}$, J. Blasco $^{1 *}$ \\ ${ }^{1}$ Centro de Agroingeniería. Instituto Valenciano de Investigaciones Agrarias (IVIA), Ctra. Moncada-Náquera km 5. 46113 Moncada \\ (Valencia), Spain.e-mail:blasco_josiva@gva.es \\ ${ }^{2}$ Instituto Interuniversitario de Investigación en Bioingeniería y Tecnología Orientada al Ser Humano. Universitat Politècnica de \\ València. Camino de Vera s/n, 46022 Valencia, Spain \\ ${ }^{3}$ Dpto. de Ingeniería Rural y Agroalimentaria. Universitat Politècnica de València, Camino de Vera s/n, 46022 Valencia, Spain \\ ${ }^{4}$ Dpto de Ingeniería Civil y Agrícola. Universidad Nacional de Colombia - Sede Bogotá. Carrera 30 No. 45-03, Edificio 214, Oficina \\ 206. Bogotá, Colombia
}

\begin{abstract}
The mechanisation and automation of citrus harvesting is considered to be one of the best options to reduce production costs. Computer vision technology has been shown to be a useful tool for fresh fruit and vegetable inspection, and is currently used in post-harvest fruit and vegetable automated grading systems in packing houses. Although computer vision technology has been used in some harvesting robots, it is not commonly utilised in fruit grading during harvesting due to the difficulties involved in adapting it to field conditions. Carrying out fruit inspection before arrival at the packing lines could offer many advantages, such as having an accurate fruit assessment in order to decide among different fruit treatments or savings in the cost of transport and marketing non-commercial fruit. This work presents a computer vision system, mounted on a mobile platform where workers place the harvested fruits, that was specially designed for sorting fruit in the field. Due to the specific field conditions, an efficient and robust lighting system, very low-power image acquisition and processing hardware, and a reduced inspection chamber had to be developed. The equipment is capable of analysing fruit colour and size at a speed of eight fruits per second. The algorithms developed achieved prediction accuracy with an $\mathrm{R}^{2}$ coefficient of 0.993 for size estimation and an $\mathrm{R}^{2}$ coefficient of 0.918 for the colour index.
\end{abstract}

Keywords: assisted harvesting, mobile platform, machine vision, smart camera, fruit pre-grading, citrus fruits 
1 28 3 429 5

Field harvesting represents between $30 \%$ and $60 \%$ of the production costs that contribute to the final product price (Ruiz-Altisent et al. 2004). During the harvesting operation, workers detach fruits and put them into picking bags or in boxes on the ground. As soon as a box is full, it is transported manually to the area where the trailers are parked to be sent to the post-harvest packing lines. It is important to note that this picking pattern is inefficient and involves dead times. To alleviate this situation, citrus harvest mechanisation and automation is being studied extensively with a view to reducing production costs (Torregrosa et al. 2009; Ortiz et al. 2011).

Robotic systems have been widely studied in precision agriculture for use in several tasks such as detecting and eliminating weeds (Lee et al. 1999; Blasco et al. 2002), yield mapping (Qiao et al. 2005) or automatic harvesting of fruit and vegetables (Qiao et al. 2004; Kondo 2009). Edan et al. (2000) proposed a system for melon harvesting using a computer vision system, but it needed $15 \mathrm{~s}$ to detect and harvest each fruit. Baeten et al. (2008) described the construction and functionality of an autonomous fruit-picking machine for robotic apple harvesting, consisting of a fruit gripper capable of detecting and harvesting fruit on the tree in $10 \mathrm{~s}$ using a CCD camera mounted on the centre of the gripper. Muscato et al. (2005) developed an autonomous robot for picking citrus and handling crates, with a fruit picking time of $8.7 \mathrm{~s}$ per orange. This system was assisted by a GPS loaded with a pre-programmed route. Among the most common disadvantages of these robotic systems are the long picking times per fruit, the difficulty involved in detecting fruit hidden by other fruits or leaves (Lee and Slaughter 2004) and the mechanical damage that could be caused to fruit and parts of the tree, such as branch breakage. Therefore, the mechanical properties of fruit must be studied to ensure robotic grippers for handling fruit are designed properly ( $\mathrm{Li}$ et al. 2011). In contrast, Chong et al. (2008) presented a robot for grading aubergines while they were being harvested that was also capable of working in greenhouses where conditions are more controlled than in field crops. The use of robots for smart harvesting in greenhouses is becoming a key aspect of precision agriculture, this work being a good example.

An alternative system to robotic harvesting could be the use of mobile platforms to assist harvesting tasks. Although they cannot accomplish automatic harvesting, they can assist manual harvesting. However, since the early developments of Jutras and Coppock (1958) or Coppock and Jutras (1960), little progress has been made in the use and possibilities of 
mobile platforms to assist in citrus collection besides modernising the vehicles. Now, the advance of computer vision technology and global satellite navigation systems allow the incorporation of high performance inspection systems capable of pre-grading the fruit in the field. One of the main advantages of these platforms is that, simultaneously, they could also carry out other tasks in addition to fruit harvesting, such as crop monitoring (Mazzetto et al. 2010; Nieuwenhuizen et al. 2010) or product inspection and pre-sorting. As stated by McBratney et al. (2005), some of the competitive advantage of precision agriculture will come from the in-field separation of product into quality classes. Infield pre-sorting allows inferior quality fruit to be separated from marketable fruit and has the potential to help growers achieve significant cost savings in post-harvest sorting, grading and storage (Mizushima and Lu 2011). This process is particularly important in the case of citrus fruits in order to detect and sort fruit with different colours that require postharvest de-greening. This is especially so at the beginning of the season when citrus have reached the optimum stage of maturity but have still to reach the correct external colour. As a result, depending on their colour at the outset, they will need different de-greening treatments.

An in-field pre-grading system would allow immediate decisions to be made about the final use of fruit, as well as more efficient management of the post-harvest grading line. Furthermore, in-field sorting of small-sized or damaged fruits can avoid unnecessary transporting of low quality products which are destined for the processing industry. Taking these low-quality fruits directly from the field to the processing plant would lead to a reduction in costs.

Automatic pre-grading could be carried out by computer vision systems. In fact, vision system technology has been largely developed for automatic quality inspection of fruits and vegetables in grading lines of packing houses (Blasco et al. 2009a; Cubero et al. 2011; Lorente et al. 2012). However, there are large differences between computer vision systems designed to work indoors under controlled conditions and unlimited availability of power, and equipment designed to work in field conditions on vehicles that are moving over irregular land. For instance, Ehsani et al. (2009) developed a computer vision system located in a shaking mechanical harvester capable of counting the number of harvested fruits in order to assess harvesting yield. However, this development has several problems and only works under laboratory conditions due to the difficulties mentioned in moving this technology from the packing lines to the field. A similar approach was taken by Feng et al. (2008), who developed a robotic arm for strawberry detachment and 
grading based on colour information, but all the experiments were carried out under selected samples of fruit and very controlled laboratory conditions.

This work addresses the development of a computer vision system for fruit inspection mounted on a harvesting platform that was specially designed to work in field conditions (Cubero et al. 2010). The main demands this equipment must fulfil if it is to be mounted on field machinery are: small size, low electricity consumption to be powered by the platform battery, and highly optimised algorithms to process all the harvested fruit in real time. A mobile platform to pre-sort citrus fruit in the field similar to the one presented in this work was described by Kohno et al. (2011). The approaches and solutions taken in the two studies to achieve a system capable of working in field conditions are different, although with similar aims. These differences will be discussed in the results section.

\section{Objective}

The main objective of this research was to develop optimised solutions for fruit inspection capable of working on field machinery. In order to inspect all the harvested fruit, this system should be able to inspect the size and colour of eight fruits per second travelling on a conveyor belt. It should be small enough to be mounted on a self-propelled platform used for testing the inspection system and wholly powered by the platform battery, this being a critical point. In addition, the vision system has to be capable of classifying the fruit into three categories (a restriction of the platform that can only separate the fruit mechanically into three categories). Therefore, the following challenges had to be overcome:

- Due to the height of the mobile platform used to assist in fruit harvesting and the fact that the inspection system will logically be situated on the top, the inspection chamber should be as small as possible.

- To develop a uniform, robust and efficient lighting system. It is very important to minimise the power consumption because it is supplied by the battery of the machine. On the other hand, it is also important to have a robust lighting system, capable of withstanding field conditions and easy to maintain. Moreover, it has to illuminate the whole scene in a uniform manner. 
- To develop real-time fruit image acquisition and processing algorithms to classify fruit into three categories according to size and colour.

\section{Inspection chamber}

Inspection chamber development

In a traditional design for vision systems to be used in fruit inspection, the camera is located above the conveyor belt, which requires a high inspection chamber. However, field machines need to be transported by road and stored at the farm storage facility, so the inspection chamber needs to be easy to dismantle for transporting and maintenance. This fact implies new design and assembly conditioning factors, especially with regard to the high location of the camera. An assessment of the characteristics of the vision system is required to develop a new design that avoids the traditional design principles.

An easy solution could be to use a wide-angle lens but then other problems arise. For instance, to obtain a scene that includes eight fruits in the image as in this work, a standard $4 \mathrm{~mm}$ lens ( $64^{\circ}$ field of view) should be placed at a height of $320 \mathrm{~mm}$ above the samples. Taking into account the size of the camera, the inspection chamber would be higher than $500 \mathrm{~mm}$, which exceeds the limitations of this application. In addition, other problems such as distortion of the image occur and hence a different solution is envisaged. Accordingly, the height of the camera was reduced by bending the light path $45^{\circ}$ using a mirror and mounting the camera horizontally, as shown in Figure 1.

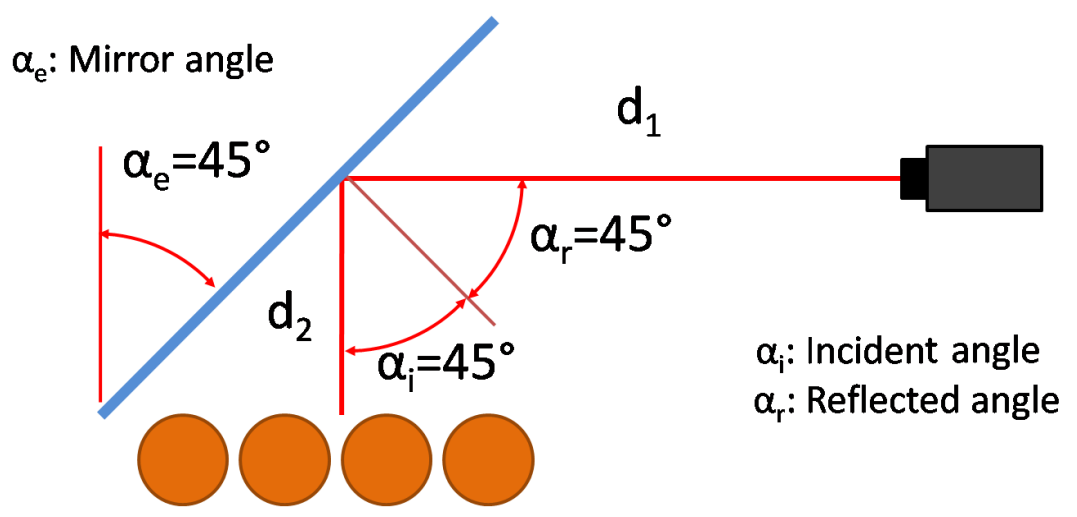

Figure 1. Camera arrangement with the mirror oriented $45^{\circ}$ with respect to the scene plane 
By so doing, the total height of the inspection chamber was reduced to only $330 \mathrm{~mm}$ from the conveyor belt to the top of the cover. The second requirement fulfilled by this design was an easy mounting and dismounting process, since it is light and easy to handle. In order to avoid temperature problems inside the chamber, two fans were placed in the stainless steel cover to extract hot air and reduce the effects of the potentially high working temperature that can be reached outdoors. The final design without the cover is shown in Figure 2.

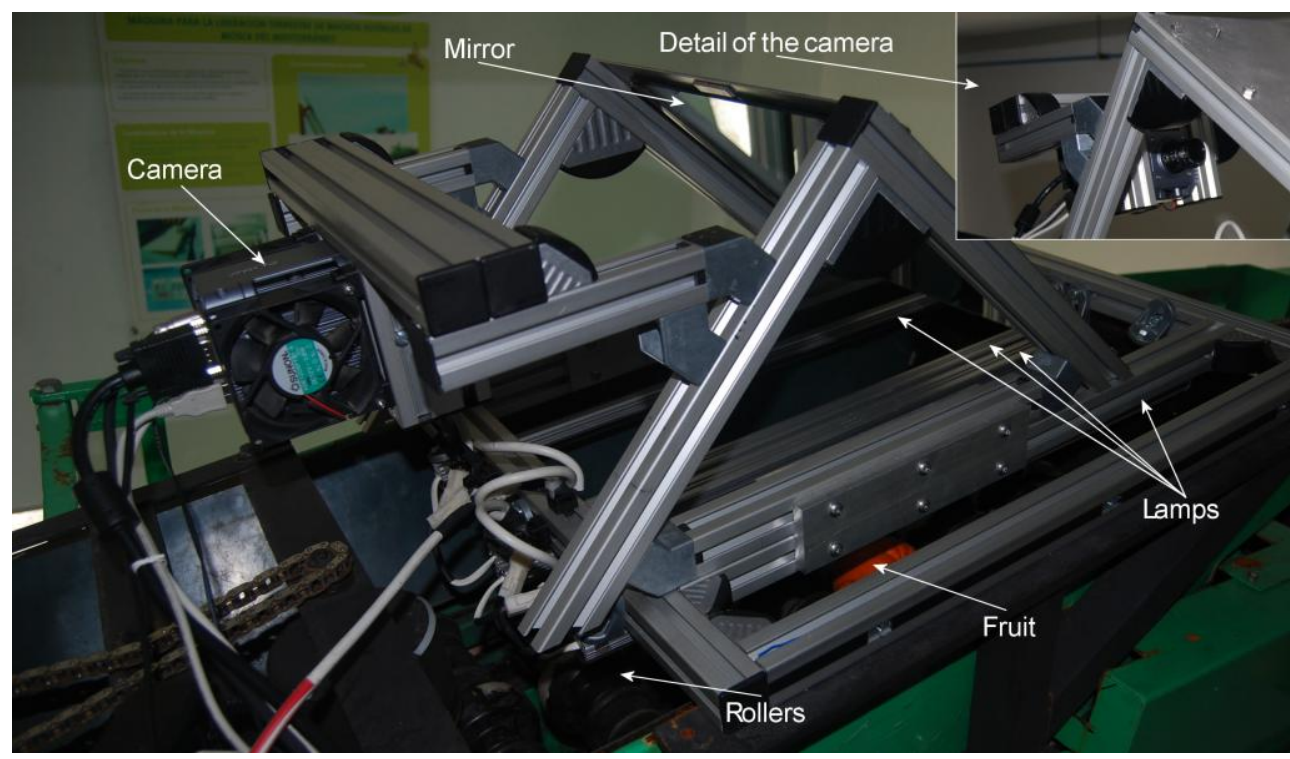

Figure 2. Arrangement of the elements of the computer vision system in the inspection chamber

Image capture system

Fruit is conveyed by means of rollers. Each fruit travels between two rollers that rotate as it passes under the field of view of the camera. In order to acquire the images, an intelligent camera with processing capability was used. This kind of camera allows the image to be captured and processed without using a computer, which offers some advantages, such as the possibility of using direct current (DC) $12 \mathrm{~V}$ from the battery of the platform. On the other hand, it is ten times slower at running the same algorithm than a common computer (compared to an Intel Core 2 Duo $2.9 \mathrm{GHz}$ ). A compromise between accuracy and processing speed was required, which called for the development of highly optimised algorithms. However, this meant the loss of some complex functions, such as analysing the contour of the 
objects found in the image, which could probably have achieved better results in the size estimation or the inspection of external defects (Gómez-Sanchis et al. 2008; Blasco et al. 2009b).

In this work, a colour progressive scan camera (XCI-SX100C/XP, Sony Corporation, Japan) capable of acquiring images in RGB format (red, green, blue) with a resolution of $1280 \times 969$ pixels was chosen. Besides acquiring the images, the camera itself was also able to analyse the images by means of a built-in microprocessor VIA Eden ULV 1 $\mathrm{GHz}$ that runs the Windows XP Embedded ${ }^{\circledR}$ (Microsoft Corporation, USA) operating system. Additional important features are digital inputs and outputs to activate lighting, reading the encoder pulses as well as activating the external trigger or interacting with the control of the mobile platform. The camera is DC-powered with a maximum power consumption of $18.2 \mathrm{~W}$. An $8 \mathrm{~mm}$ lens was used to capture images with a resolution of $0.31 \mathrm{~mm} / \mathrm{pixel}$. Image capture starts when the camera receives an external trigger signal from a pulse encoder synchronised with the movement of the conveyor belt.

In order to scan the maximum fruit surface, it is necessary to capture and analyse several images of each piece of fruit as they roll through the camera scene at a speed of $400 \mathrm{~mm} / \mathrm{s}$. More specifically, four images were taken of each fruit. The scene was divided into four regions per line in which the images of the fruits were captured. As the fruits advance under the camera, they pass through each of these four positions with a rotating movement, thus allowing different parts of the surface to be shown to the camera in each image. These positions can be seen in Figure 3. Having four fruits per line in each image, one image is acquired each time a new fruit enters the scene (while another fruit leaves the scene); this is controlled by using the encoder. A $1 / 500 \mathrm{~s}$ ( $2 \mathrm{~ms}$ ) shutter was set since, at working speed, each fruit moves only $0.8 \mathrm{~mm}$ in this capture interval, which is within the tolerance. In addition, a GPS device (Garmin 18x USB, Garmin Ltd., Switzerland), installed on the machine and connected to the camera using the USB port, provides the location of the machine at a rate of $1 \mathrm{~Hz}$ in NMEA (National Marine Electronic Association) format. By so doing it becomes possible to track the path followed by the mobile platform while harvesting the fruit and to generate files in KML (Keyhole Markup Language), which is a format compatible with the application Google Earth (Google Inc, USA). Similarly, POIs (points of interest) showing data about the harvested fruit can be added to the path. 


\section{Lighting system design}

Lighting is one of the most important elements in computer vision. It is very important to provide uniform and stable illumination over the whole scene so as to avoid shadows and bright spots. In this particular development, due to the power limitations of an autonomous vehicle such as the mobile platform, low power lighting is required. Moreover, field conditions require a robust and low maintenance system. The solution adopted is based on strips of LEDs (lightemitting diode) placed above the fruit. The LED strips were $600 \mathrm{~mm}$ long and contained 50 LEDs. The light intensity is $20 \mathrm{~lm} / \mathrm{cm}$, which is enough for this application. One advantage of LEDs is that they make it possible to work in stroboscopic mode, which means that the diodes are only switched on for image acquisition (similar to a photographic flash). The strobe signal needs to be synchronised with the camera and triggered with the image capture. To do this, an electronic board based on a microcontroller was developed specifically for this application. According to the estimations carried out, working at a speed of 4 images per second and setting the LED exposure time to 4 ms (the acquisition time is $2 \mathrm{~ms}$ ), the strips of LEDs are switched on for only $8 \mathrm{~ms} / \mathrm{s}$ (less than $1 \%$ of the time).

Bright spots on the surface of the oranges can lead to false colour measurements. To reduce this problem, crosspolarised light was used by placing polarising filters in front of the LEDs and the camera lens. Another important advantage of the use of stroboscopic illumination is the reduction of heat, which allows the polarising filter to be inserted inside the protective covers of the LED strips. Figure 3 shows the configuration diagram and the simplicity of the design. 


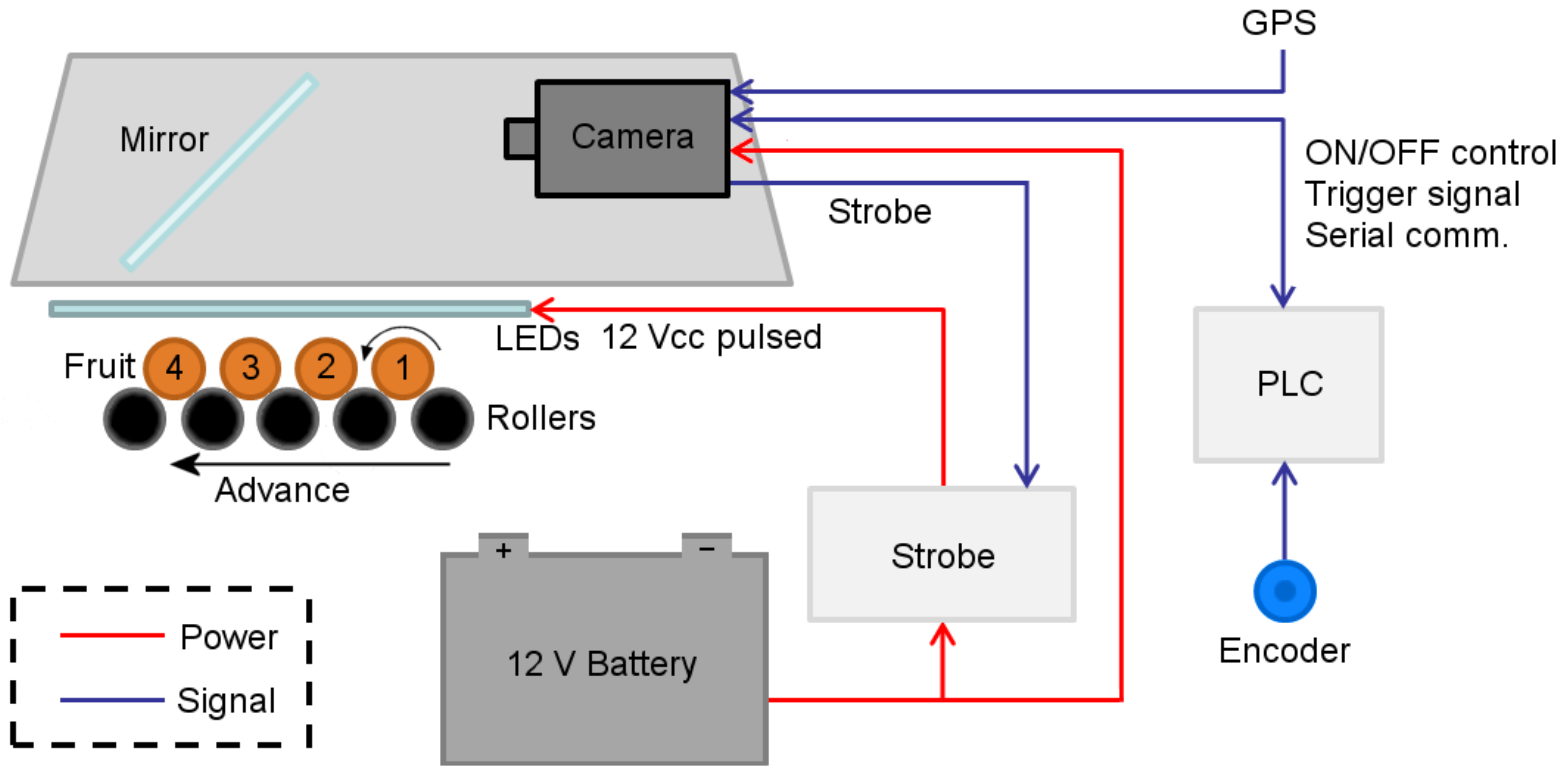

Figure 3. Diagram of the whole computer vision system developed. The numbers inside the fruits mean the four positions in which the system acquires the images of each fruit.

\section{In-line grading system}

The relatively low computational capacity of the camera determines the design of the algorithm, the flowchart for which is shown in Figure 4. The algorithm was implemented in programming language $\mathrm{C}$ without the use of external imageprocessing libraries to allow total control of the inspection process. It was compiled to run under the Microsoft Windows operating system using the open source compiler wxDEV-C++ (http://wxdsgn.sourceforge.net). 


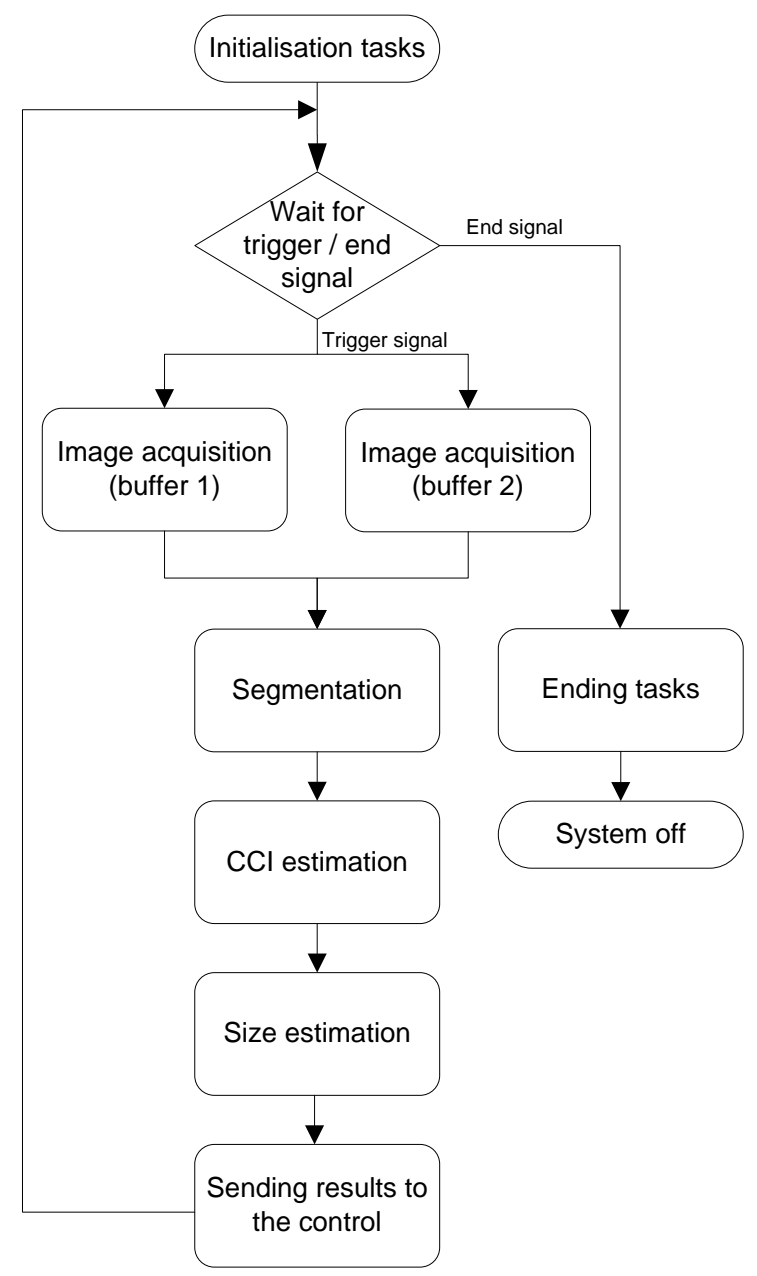

Figure 4. Flow chart of the algorithm for the in-line processing of citrus fruits

Image acquisition

The camera needs $40 \mathrm{~ms}$ to acquire an image following the CCIR (Comite Consultatif International des Radiocommunications) standard. An image cannot be processed until it is totally acquired. However, this camera allows the acquisition of one image whilst processing the previous one, thus saving a total of $40 \mathrm{~ms}$ in the overall process. This technique is called double buffering and consists in using two memory buffers alternatively for image acquisition, storage and processing. After receiving a new trigger pulse, as the processing of one image lasts for more than $40 \mathrm{ms,}$ while the image $\mathrm{A}$ is being processed, the image $\mathrm{B}$ is being acquired and stored in the memory buffer until the processing of image A finishes. In that moment, the image B is processed while the system waits for the next trigger 
6

signal to start a new acquisition. In any case, all the algorithms must be executed in a shorter time than that elapsed between two consecutive trigger pulses, otherwise an image can be lost.

\section{Segmentation}

Due to the optimisation required to achieve working performance, the whole image analysis had to be performed in only one image loop. On this basis, the segmentation method implemented also extracted all the object features in the same step. The camera provides images in RGB (red, green, blue) format which means that the each pixel in the image is represented by three individual values of $\mathrm{R}, \mathrm{G}$, and $\mathrm{B}$. In order to segment the image, a green and blue band ratio (G/B) based on the RGB value of each pixel was used. All pixels with a G/B ratio above a certain threshold were considered fruit and the rest were considered background. This ratio was chosen because fruit have low blue values and high green values at all stages of maturity, while background always has low blue and green values

\section{Size estimation}

To optimise performance, instead of estimating the size of the fruit from its contour, which would involve extracting and analysing the perimeter of the fruit and calculating the centroid to search for the largest or average diameter, the fruit size was estimated indirectly from the area measurement. Firstly, the area was calculated as the sum of all the pixels belonging to the fruit when the image was being segmented. Then, the diameter was calculated using the equation of the area enclosed by a circle (1).

$$
d=2 \times \sqrt{A / \pi}
$$

where $d$ is the estimated diameter (size) of the fruit and $A$ is the area obtained.

The fruit size was calculated as the average of the partial size of each image acquired from the same fruit. This approach could be taken because the fruit to be inspected by the mobile platform were oranges and mandarins. In the case of lemons or other kinds of non-spherical fruit, a different approach could be used instead. This might involve the minimum bounding box since, as the fruit are rotating while advancing, they are normally oriented along the rotating 
6

axis and therefore the difference between the higher and lower $\mathrm{x}$ and $\mathrm{y}$ co-ordinates would be a good approximation of the size.

Colour index estimation

Sometimes, early season mandarins are harvested when they have reached an acceptable organoleptic ripening stage but their external colour is still turning from green to orange. In these cases, an ethylene treatment is applied to accelerate the development of the typical orange colour. The treatment duration depends, among other factors, on the initial colour, so it could be very useful for producers to have pre-sorted fruit arriving at the packing house. In order to grade colour, the Citrus Colour Index (CCI) (Jiménez-Cuesta et al. 1981) is used in the industry and is calculated according to equation (2) from the $L, a, b$ HunterLab values obtained using a spectrophotometer. Figure 5 shows an example of the appearance of an orange with different CCI values, although in the real world the colour is not so uniform over the entire surface.

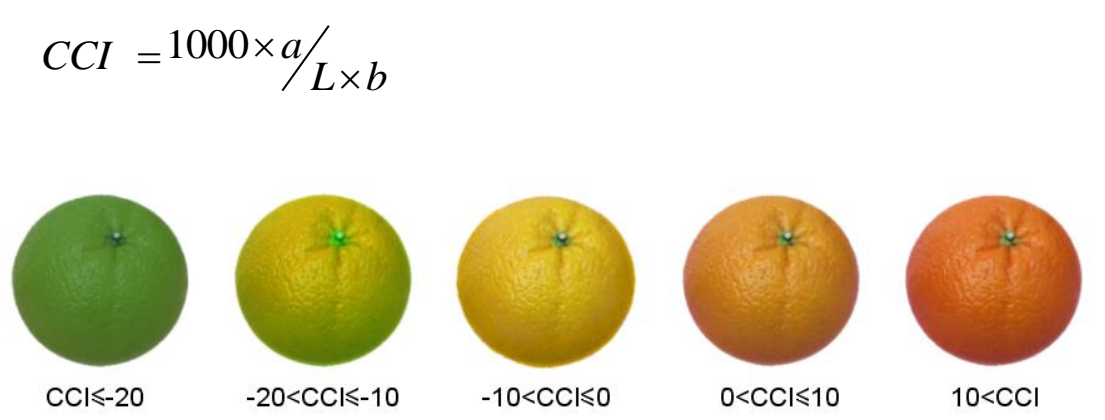

Figure 5. Different values of the CCI of an orange and its appearance

In computer vision systems, image colour values are given in RGB co-ordinates and so it is necessary to convert them to the HunterLab colour space to estimate the colour index. The LEDs used in this platform have a colour temperature of $6000 \mathrm{~K}$. Therefore, the equations used to perform the conversion include a D65 $(6500 \mathrm{~K})$ illuminant and a $10^{\circ}$ observer reported by HunterLab (2008). The average RGB values of the four images were calculated individually with the image segmentation process. After segmentation, the average RGB value was converted to HunterLab co-ordinates 
so that the CCI of that image could be calculated as the average CCI obtained from the four images of the fruit (Vidal et al. 2012).

\section{Tests}

A total of 225 'Navelina' oranges were used to assess the prediction and classification ability of the equipment. Fruit were randomly selected from just-harvested fruit at the orchards of IVIA, Valencia, Spain, and covered a range of different sizes and colours (from light green to orange colour).

All fruit were measured manually using a digital calliper. The equatorial diameter of the fruit was calculated as the average of the measurements performed by three different operators. These data were compared to those estimated by the vision system and the R-squared coefficient was used to quantify the magnitude of the linear relationship. In addition, fruit were classified into three size categories (the mechanical limit of the mobile platform), one for noncommercial small-sized fruit and two other commercial categories:

- Category 1: [diameter $<65 \mathrm{~mm}]$

- Category 2: $[65 \mathrm{~mm}<$ diameter $<80 \mathrm{~mm}$ ]

- Category 3: [ $80 \mathrm{~mm}<$ diameter]

To evaluate the performance of the system in colour estimation, each fruit was measured manually using a spectrophotometer (Minolta C400, Konica Minolta Opto, Inc. Japan) at six random points. Three operators measured the colour in the four positions and the average of the three operators was calculated. In order to assess the colour prediction ability of the vision system, the correlation between the spectrophotometer measurements and the vision system measurements was calculated. In addition, as in the case of the size estimation, fruit were classified into three colour categories according to the recommended de-greening treatments (DOGV 2006):

- Category 1: [ CCI <3]

- Category 2: $[3<\mathrm{CCI}<7]$

- Category 3: $[7<\mathrm{CCI}]$ 


\section{Results}

1 258 3 259 5 260 261 10

The system developed was tested mounted on a mobile platform to assist in the harvesting of citrus fruits, but it can easily be adapted to other vehicles that could move the fruit under the camera and mechanically sort the fruit according to the decisions taken by the automatic system. Furthermore, the algorithms that were developed could also be adapted for use with other spherical fruits like apples or peaches.

A critical restraint for any in-line process is the processing speed. To measure the performance of the algorithms, a total of 20 images were tested, each containing eight fruits with different colours and sizes in an attempt to reproduce the most complicated scene. The maximum time required by the system to process one of these images was $125 \mathrm{~ms}$, the measurements being performed using an oscilloscope connected to one of the digital outputs of the camera to which a signal was sent when starting and finishing the process. This time accomplishes the real-time specifications of the system.

\section{Size assessment}

The size of the fruit was assessed from the area estimated as the sum of all pixels belonging to the fruit according to equation (1). A linear regression model was established by comparing the size measured manually with the size estimated by the automatic system. The linear model correlation coefficient was 0.99 with an adjusted R-squared of 99.3\%, showing statistically significant coefficients and standard error clearly under $1 \mathrm{~mm}$ (Table 1). Figure 6 shows the adjusted linear model.

Table 1. Regression analysis (manual-image analysis vs. size estimation)

\begin{tabular}{lrrrr}
\hline \multicolumn{1}{c}{ Parameter } & \multicolumn{1}{c}{ Estimation } & Standard Error & \multicolumn{1}{c}{ T } & \multicolumn{1}{c}{ P-value } \\
\hline CONSTANT & -0.907172 & 0.179073 & -5.06593 & 0.0000 \\
Size & 1.01374 & 0.00244685 & 414.305 & 0.0000 \\
\hline
\end{tabular}




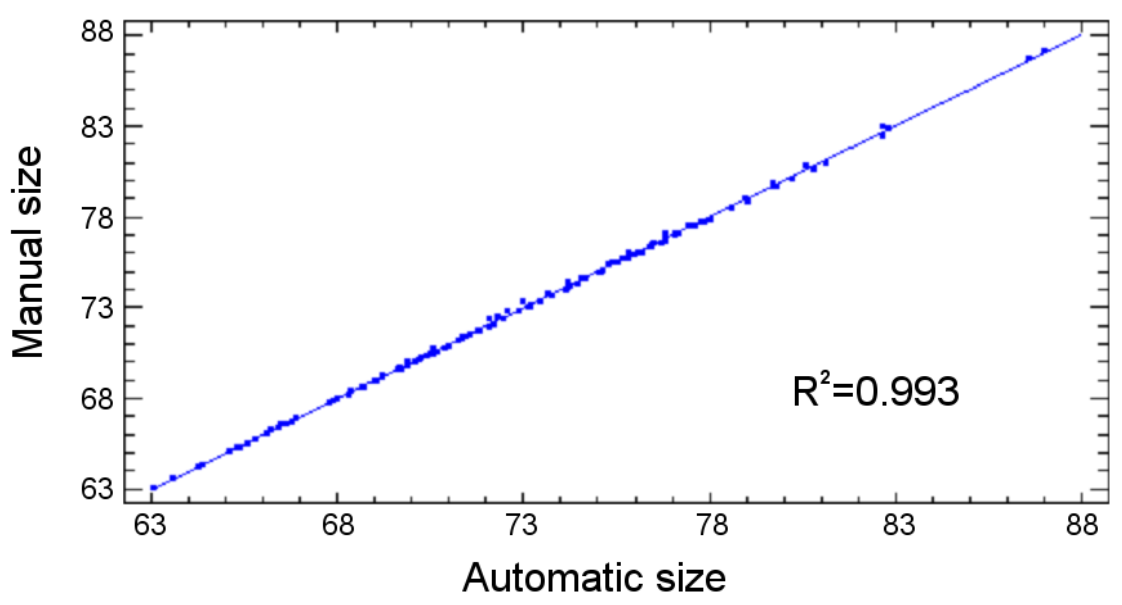

Figure 6. Linear model obtained for the size measurement (in mm)

With regard to the classification of the fruit by size, $100 \%$ success was achieved for all the categories (Table 2). This fact was due to the excellent adjustment of the model, with a standard error under $1 \mathrm{~mm}$, which would be unrealistic in the real world, particularly in the case of non-spherical or elongated cultivars. However, it also demonstrated the high degree of accuracy obtained by the methods developed: the error that the system could achieve would be below the $10 \%$ commercial tolerances (Official Journal of European Communities 2001).

Table 2. Confusion matrix of the classification of the fruit by size achieved by the mobile platform using the computer vision system

\begin{tabular}{lccc}
\hline & Category 1 $(\%)$ & Category 2 $(\%)$ & Category 3 $(\boldsymbol{\%})$ \\
\hline Category 1 (size $<65 \mathrm{~mm})$ & 100.0 & 0.0 & 0.0 \\
Category 2 (size $[65 \mathrm{~mm}-80 \mathrm{~mm}])$ & 0.0 & 100.0 & 0.0 \\
Category 3 (size $>80 \mathrm{~mm})$ & 0.0 & 0.0 & 100.0 \\
\hline
\end{tabular}

Colour assessment

The average fruit CCI from the spectrophotometer was correlated to the CCI calculated with the automatic system. A quadratic regression was performed. The model correlation coefficient was 0.94 and the adjusted R-squared $91.8 \%$. Table 3 shows the significance of all the coefficients, so the model is considered adequate having a high R-squared. The quadratic model correlation could be explained by the fact that the actual difference between the CCI values is not 
uniform. Greater colour heterogeneity is found in oranges that are in the range of CCI between 3 and 7 , where the colour is changing from green to orange. Lower values correspond to green oranges while higher values are determined by fruit with a uniform orange colour. Therefore, the differences between fruit outside this range are perceptually lower.

In addition, the colour of a fruit with a CCI between 3 and 7 can vary from some areas of the skin to another, since the

Table 3. Regression analysis CCI (Spectrophotometer vs. image analysis)

\begin{tabular}{lrrrc}
\hline \multicolumn{1}{c}{ Parameter } & Estimation & Standard Error & \multicolumn{1}{c}{ T } & P-value \\
\hline CONSTANT & 7.76659 & 0.128735 & 60.3298 & 0.0000 \\
CCI equipment & 0.378798 & 0.00786441 & 48.1662 & 0.0000 \\
CCI equipment $^{\wedge} 2$ & 0.00249006 & 0.000408488 & 6.09579 & 0.0000 \\
\hline
\end{tabular}

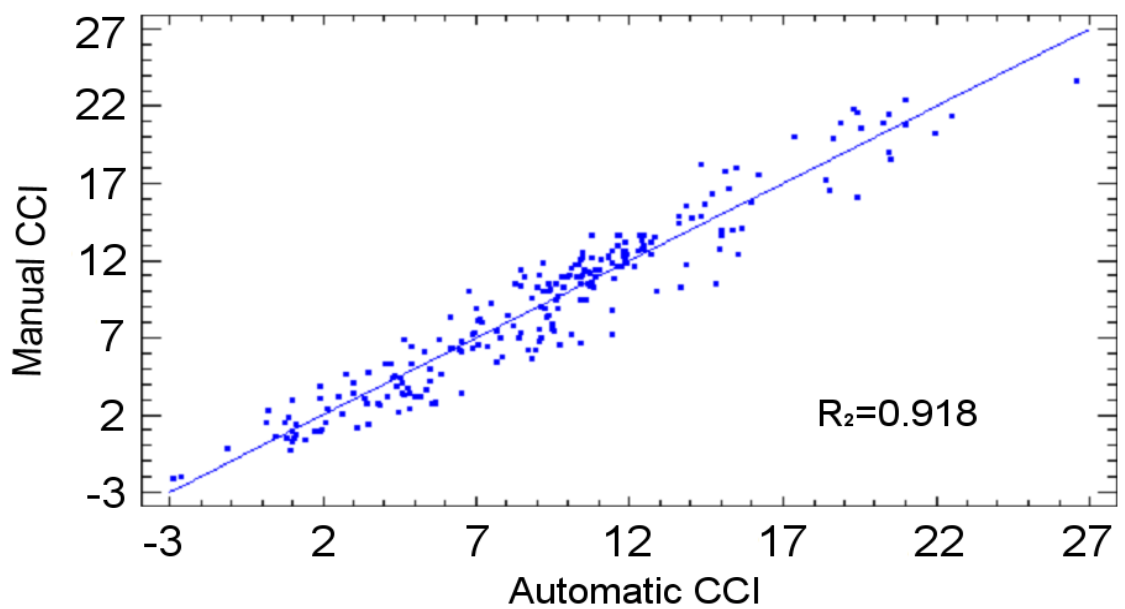

Figure 7. Regression model for the CCI (Spectrophotometer vs. image analysis)

Table 4 shows the confusion matrix obtained with both manual and automatic systems. The best results are found in category 3 (orange fruit). In contrast, fruit from category 1 presented a homogeneous light green colour that is sometimes near the threshold of category 2 , which includes mostly fruit with a green colour and some yellow regions.

Table 4. Confusion matrix of the classification of the fruit by colour achieved by the mobile platform using the computer vision system

Category $1(\%) \quad$ Category $2(\%) \quad$ Category $3(\%)$




\begin{tabular}{lccc} 
Category $1(\mathrm{CCI}<3)$ & 84.0 & 16.0 & 0.0 \\
Category 2 & 0.0 & 90.7 & 9.3 \\
$(3<\mathrm{CCI}<7)$ & 0.0 & 1.9 & 98.1 \\
Category $3(\mathrm{CCI}>7)$ & & & \\
\hline
\end{tabular}

The system developed for pre-grading fruit on a mobile platform obtained good results and showed good performance during the tests. The use of a smart camera makes the maintenance of the prototype simpler as well as making the mechanical and electrical assembly more robust, but at the expense of reduced performance. A faster industrial $12 \mathrm{~V}$ computer could probably be used instead of the built-in microprocessor of the camera, since all the software developed is compatible, but the complexity of the system arrangement and maintenance would also increase. In any case, at the time of the study and for the sake of simplicity and effectiveness, the use of this camera was considered the best option.

Kohno et al. (2011) presented a mobile platform for pre-grading citrus fruits in the field but some differences can be observed between the two solutions. Their system inspected the fruit one-by-one, which allowed them to use a very wide-angle lens to reduce the height of the inspection chamber. However, the system described here covers a larger scene with eight fruits which can cause a negative barrel effect. Instead, a solution based on a mirror was proposed. Although it could probably get dirty during a harvesting operation, there were no problems during the tests that affected image segmentation. With this solution, a more reduced height of the inspection chamber was achieved than would have been possible using a wide-angle lens. Another difference is that the system described here can be powered using the battery of a self-propelled vehicle while, in the other solution, it is not clearly explained how a standard PC that normally uses alternate current was powered. There was also no means to mechanically separate the fruit and therefore a different machine would have been needed to perform this task.

Regarding the fruit grading, eight fruits per second (enough to inspect the fruit being harvested by six workers) were inspected by taking four images of each fruit in order to analyse the maximum surface area. In contrast, in the solution proposed by Kohno et al. (2011), only one image was acquired of each fruit (no data about performance were reported), which, due to the heterogeneity in the colour distribution of the fruit surface when it is turning from green to orange, makes it difficult to obtain accurate results. However, the Kohno system only needed to sort mature and immature fruits while the proposed system grades fruit by colour to determine whether a de-greening treatment is needed. Both systems 
31

are valid solutions and present advances in the progressive incorporation of advanced technology into the field in order to reduce production costs and to provide new tools for advanced crop management. Figure 8 shows the mobile platform with the inspection system.

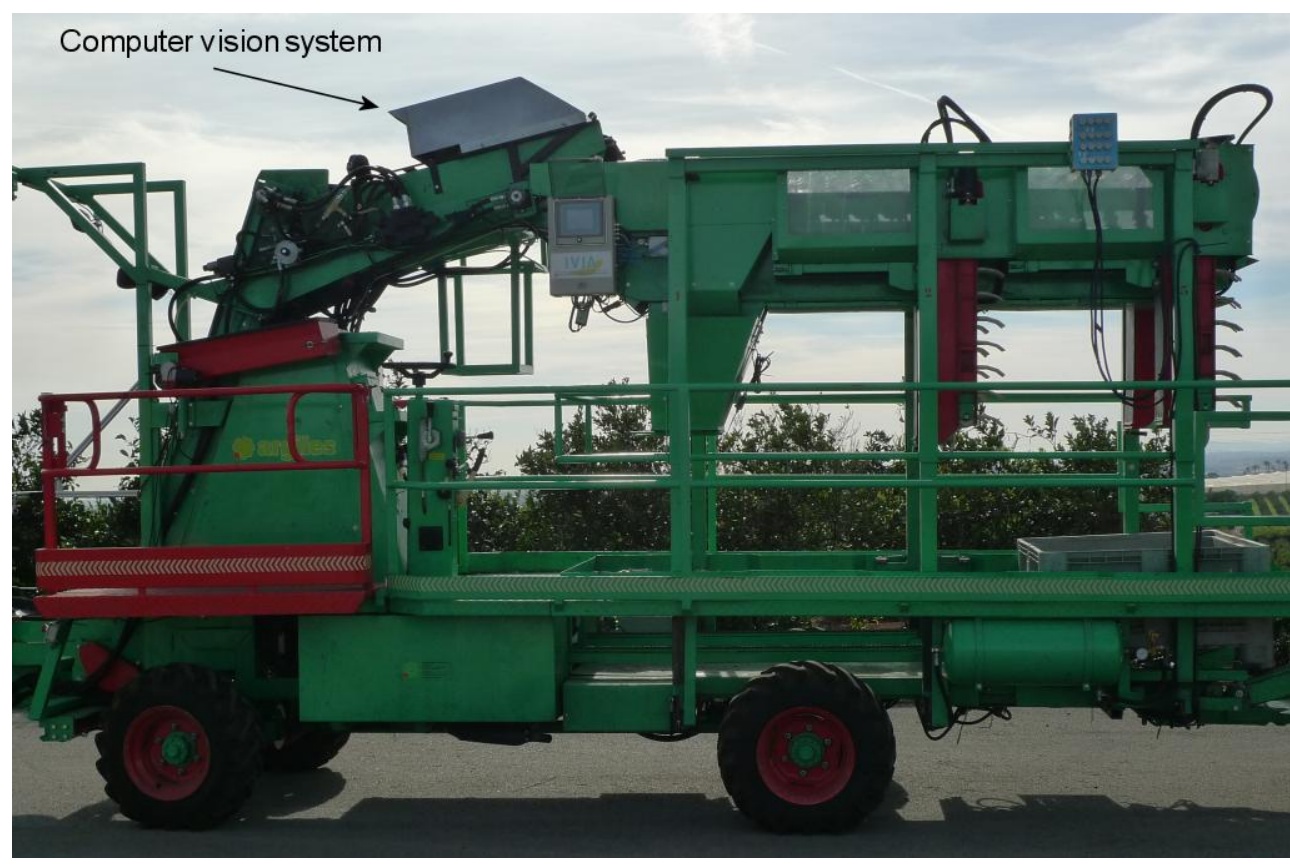

Figure 8. Mobile platform with the grading system

\section{Conclusions}

A real-time computer vision system was developed to be mounted on a mobile platform or other off-road vehicle that allows fruit pre-grading during harvesting. The arrangement and design of the image acquisition system makes it possible to construct an inspection chamber that requires an increment in the total equipment height of just $330 \mathrm{~mm}$. Moreover, the use of an image-reflecting mirror was shown to be an adequate solution compared to the traditional camera location at the top of the inspection chamber, even when using a wide-angle lens.

The use of LEDs combined with a stroboscopic technique resulted in very low power consumption, while also reducing heat dissipation so as to allow polarising filter films to be inserted within the LED covers.

Using a smart camera made it possible to simplify the computer vision application by avoiding the use of an additional computer and allowing a $12 \mathrm{~V}$ battery supply to be implemented. The low processing speed of the camera restrained the 
development of complex image analysis algorithms. However, the good scores achieved in this research in terms of prediction of colour and size features of fruit show that it is highly recommendable to use this kind of system due to the simplicity of its installation and the low electrical power consumption.

The maximum processing time per image was $125 \mathrm{~ms}$, which is sufficient for this purpose. This time allowed inspection of the fruit in-line by acquiring and analysing four images of each fruit in different views. An R-square coefficient of 99.3\% was found for size estimation, and a relatively high value of R-square (91.8\%) for colour determination.

\section{Acknowledgments:}

This research work has been funded by the Instituto Nacional de Investigación y Tecnología Agraria y Alimentaria de España (INIA) and the European FEDER funds (projects RTA2009-00118-C02-01 and RTA2009-00118-C02-02). The authors wish to thank the collaboration of the company Argilés Diseny i Fabricació, S.L.

\section{References}

Baeten, J., Donné, K., Boedrij, S., Beckers, W., \& Claesen, E. (2008). Autonomous fruit picking machine: a robotic apple harvester. Springer Tracts in Advanced Robotics, 42, 531-539.

Blasco, J., Aleixos, N., Roger, J.M., Rabatel, G., \& Moltó, E. (2002). Robotic weed control using machine vision. Biosystems Engineering, 83(2), 149-157.

Blasco, J., Cubero, S., Gómez-Sanchis, J., Mira, P., \& Moltó, E. (2009a). Development of a machine for the automatic sorting of pomegranate (Punica granatum) arils based on computer vision. Journal of Food Engineering, 90, $27-34$.

Blasco, J., Aleixos, N., Gómez-Sanchis, J., \& Moltó, E. (2009b). Recognition and classification of external skin damage in citrus fruits using multispectral data and morphological features. Biosystems Engineering, 103, 137-145.

Chong, V.K., Monta, M., Ninomiya, K., Kondo, N., Namba, K., Terasaki, E., Nishi T., \& Goto, T. (2008). Development of mobile eggplant grading robot for dynamic in-field variability sensing - manufacture of robot and performance test-. Engineering in Agriculture. Environment and Food, 1(2), 68-76.

Coppock, G.E., \& Jutras, P.J. (1960). Mechanizing citrus fruit harvesting. Transactions of the ASAE, 3(2), 130-132.

Cubero, S., Moltó, E., Gutiérrez, A., Aleixos, N., García-Navarrete, O.L., Juste, F., \& Blasco, J. (2010). Real-time inspection of fruit on a mobile harvesting platform in field conditions using computer vision. Progress in Agricultural Engineering Science, 6, 1-16.

Cubero, S., Aleixos, N., Moltó, E., Gómez-Sanchis, J., \& Blasco, J. (2011). Advances in machine vision applications for automatic inspection and quality evaluation of fruits and vegetables. Food and Bioprocess Technology, 4(4), 487 504.

DOGV (2006). Diari Oficial de la Comunitat Valenciana, 5346, 30321-30328.

Edan, Y., Rogozin, D., Flash, T., \& Miles, G.E. (2000). Robotic melon harvesting. IEEE Transactions on Robotics and Automation, 16(6), 831-834. 
Ehsani, M.R., Grift, T.E., Maja, J.M., \& Zhong D. (2009). Two fruit counting techniques for citrus mechanical harvesting machinery. Computers and Electronics in Agriculture, 65(2), 186-191.

Feng G., Qixin C., \& Masateru N. (2008). Fruit detachment and classification method for strawberry harvesting robot. International Journal of Advanced Robotic Systems, 5(1), 41-48

Gómez-Sanchis, J., Gómez-Chova, L., Aleixos, N., Camps-Valls, G., Montesinos-Herrero, C., Moltó, E. \& Blasco, J. (2008). Hyperspectral system for early detection of rottenness caused by Penicillium digitatum in mandarins. Journal of Food Engineering, 89(1), 80-86.

HunterLab. (2008). Applications note, 8(9), available at: http://www.hunterlab.com/appnotes/an08_96a.pdf. Last accessed: November 2012.

Jiménez-Cuesta, M.J., Cuquerella, J., \& Martínez-Jávega, J.M. (1981). Determination of a color index for citrus fruit degreening. In: Proceedings of the International Society of Citriculture, Tokyo (Japan). Vol. 2, pp. 750-753.

Jutras, P.J., \& Coppock, G.E. (1958). Mechanization of citrus fruit picking. Florida State Horticultural Society, 71, 201,204 .

Kohno, Y., Kondo, N., Iida, M., Kurita, M., Shiigi, T., Ogawa, Y., Kaichi, T., \& Okamoto S. (2011). Development of a mobile grading machine for citrus fruit. Engineering in Agriculture, Environment and Food, 4(1), 7-11.

Kondo, N. (2009). Robotization in fruit grading system. Sensors and Instrumentation for Food Quality, 3, 81-87.

Lee W.S., Slaughter D.C., \& Giles, D.K. (1999). Robotic weed control system for tomatoes. Precision Agriculture, 1 (1), $95-113$.

Lee, W.S., \& Slaughter D.C. (2004). Recognition of partially occluded plant leaves using a modified Watershed algorithm. Transactions of the ASAE, 47, 1269 - 1280.

Li, Z., Li, P., \& Liu, J. (2011). Physical and mechanical properties of tomato fruits as related to robot harvesting. Journal of Food Engineering, 103(2), 170-178.

Lorente, D., Aleixos, N., Gómez-Sanchis, J., Cubero, S., García-Navarrete, O.L., \& Blasco, J. (2012). Recent advances and applications of hyperspectral imaging for fruit and vegetable quality assessment. Food and Bioprocess Technology, 5(4), 1121-1142.

Mazzetto, F., Calcante, A., Mena, A., \& Vercesi, A. (2010). Integration of optical and analogue sensors for monitoring canopy health and vigour in precision viticulture, Precision Agriculture, 11(6), 636-649.

McBratney A., Whelan B., Ancev T., \& Bouma J. (2005). Future Directions of Precision Agriculture. Precision Agriculture. 6(1), 7-23.

Mizushima, A., \& Lu, R. (2011). Cost benefits analysis of in-field presorting for the apple industry. Applied Engineering in Agriculture, 27(1), 33-40.

Muscato, G., Prestifilippo, M., Abbate, N., \& Rizzuto, I. (2005). A prototype of an orange picking robot: past history and experimental results. Industrial Robot, 32(2), 128-138.

Nieuwenhuizen, A.T., Hofstee, J.W., \& van Henten, E.J. (2010). Adaptive detection of volunteer potato plants in sugar beet fields. Precision Agriculture, 11, 433-447. 
Official Journal of European Communities (2001). 14.09.2001. pp. L244/12 - L244/18. available at http://eurlex.europa.eu/LexUriServ/LexUriServ.do?uri=OJ:L:2001:244:0012:0018:EN:PDF. Last accessed May 2013.

Ortiz, C., Blasco, J., Balasch, S., \& Torregrosa, A. (2011). Shock absorbing surfaces for collecting fruit during the mechanical harvesting of citrus. Biosystems Engineering, 110, 2-9.

Qiao, J., Sasao, A., Shibusawa, S., Kondo, N., \& Morimoto E. (2004). Mobile fruit grading robot (part1)-development of a robotic system for grading sweet peppers-. Journal of the Japanese Society of Agricultural Machinery (JSAM), 66(2), 113-122.

Qiao, J., Sasao, A., Shibusawa, S., Kondo, N., \& Morimoto E. (2005). Mapping yield and quality using the mobile fruit grading robot. Biosystems Engineering, 90(2), 135-142.

Ruiz-Altisent, M., Ortiz-Cañavate, J., \& Valero, C. (2004). Fruit and vegetables harvesting systems. In: Ramdane Dris and Shri Mohan Jain (Eds.), Production practices and quality assessment of food crops, Vol. 1: Preharvest practice. Kluwer Academic Publishers, Dordrecht, The Netherlands, pp. 261-285.

Torregrosa, A., Gil, J., Ortiz, C., Ortí, E., \& Martín, B. (2009). Mechanical harvesting of oranges and mandarins in Spain. Biosystems Engineering, 104(1), 18-24.

Vidal, A., Talens, P., Prats-Montalbán, J.M., Cubero, S., Albert, F., \& Blasco, J. (2012). In-line estimation of the standard colour index of citrus fruits using a computer vision system developed for a mobile platform. Food and Bioprocess Technology. DOI: 10.1007/s1 1947-012-1015-2 (In-press). 


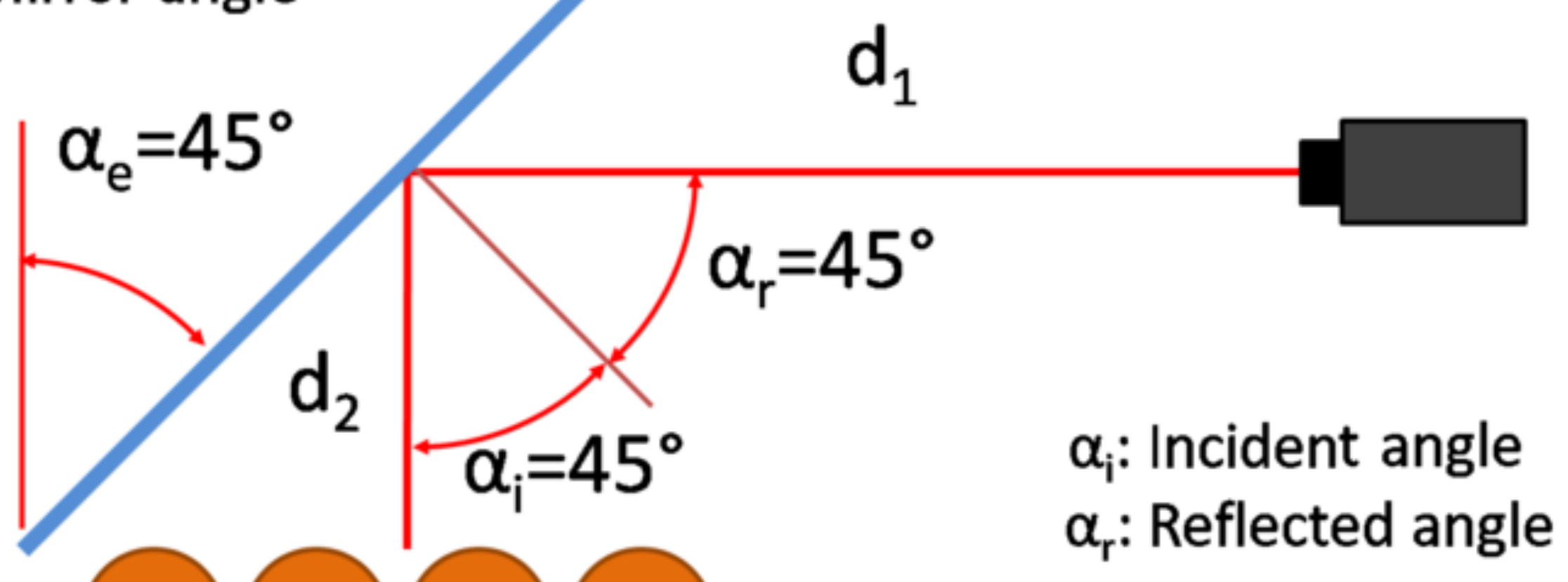

$\alpha_{i}$ : Incident angle
$\alpha_{\mathrm{r}}$ : Reflected angle 


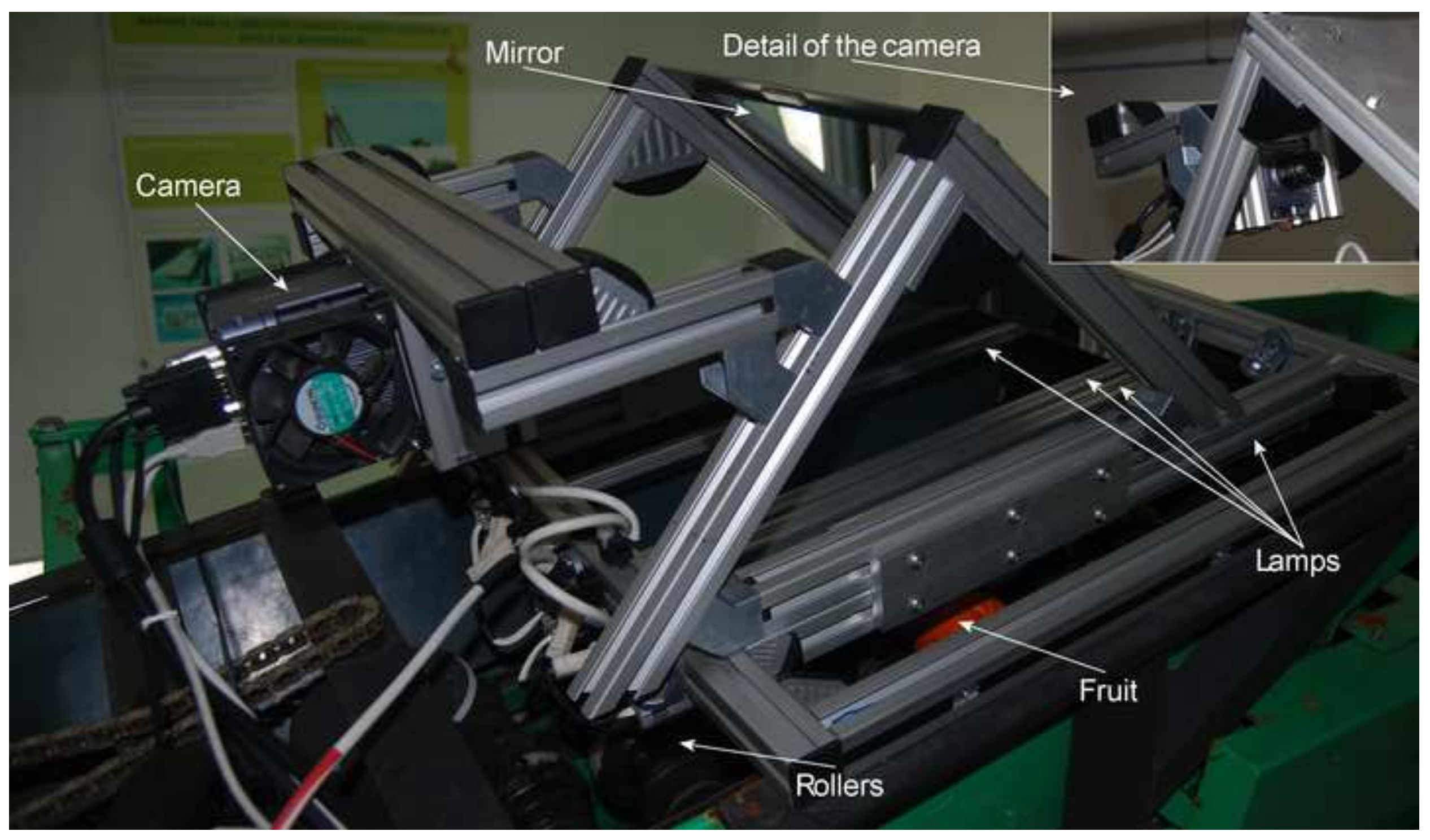




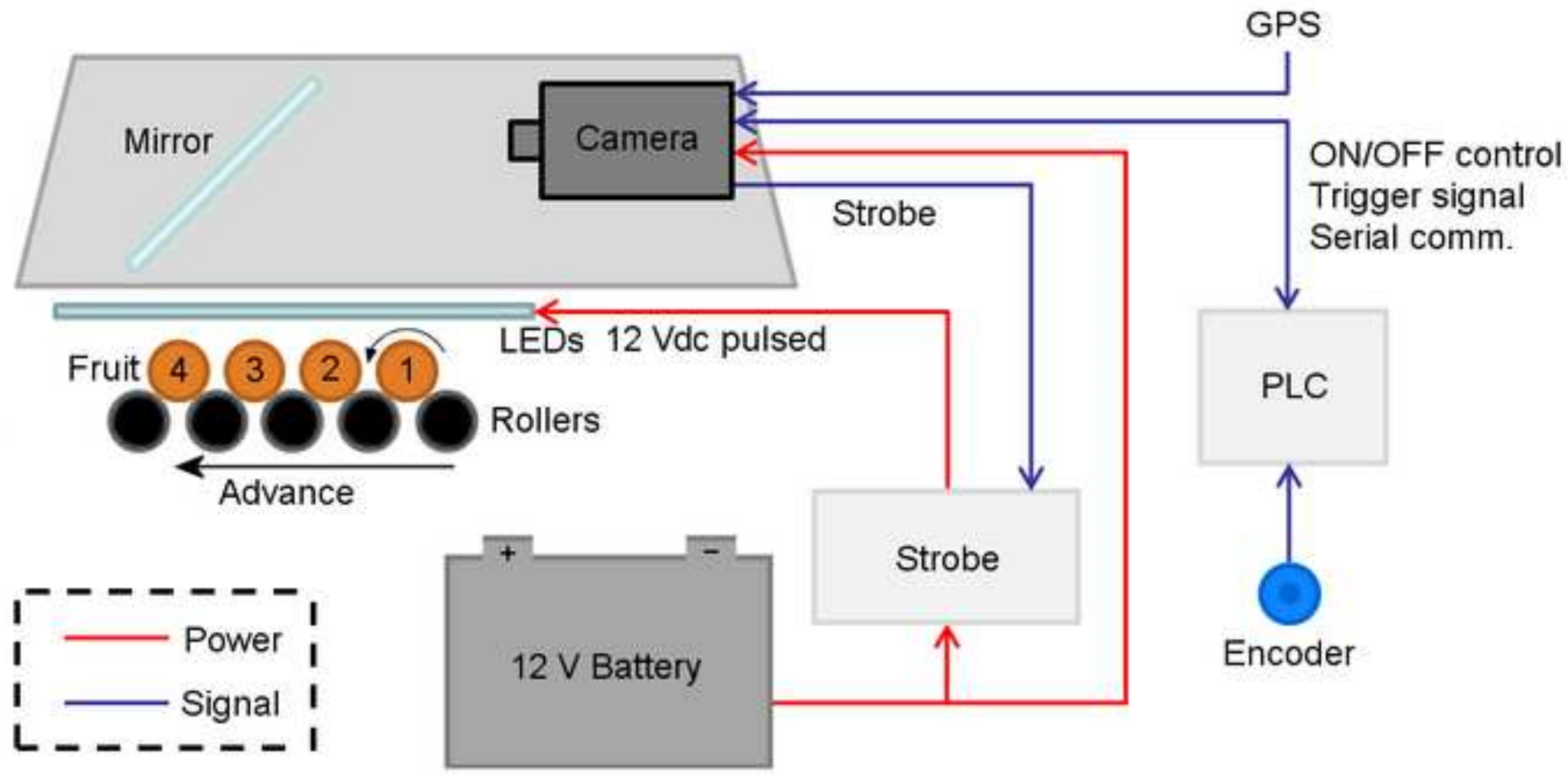




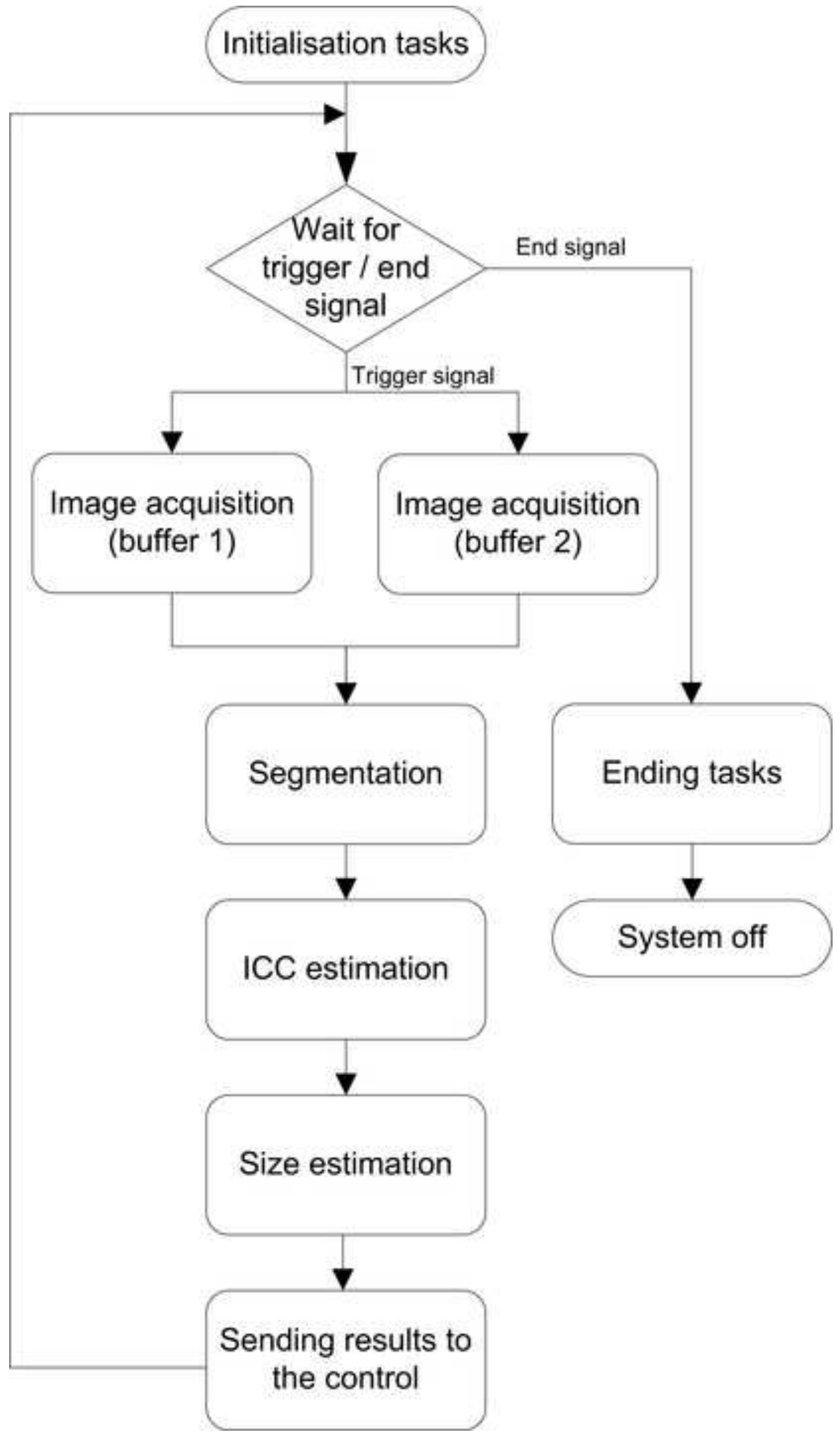




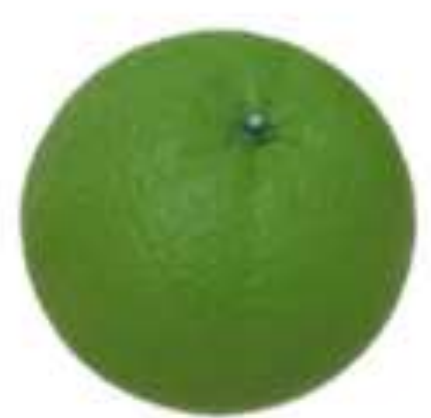

$\mathrm{CCl} \leqslant-20$

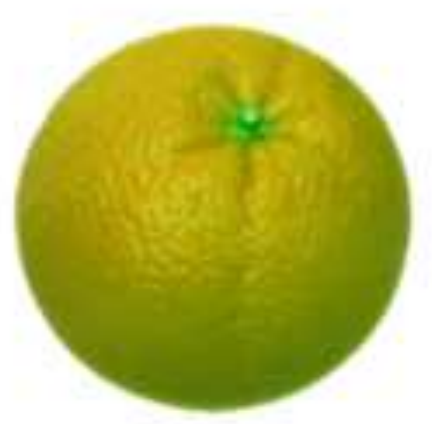

$-20<\mathrm{CCl} \leqslant-10$

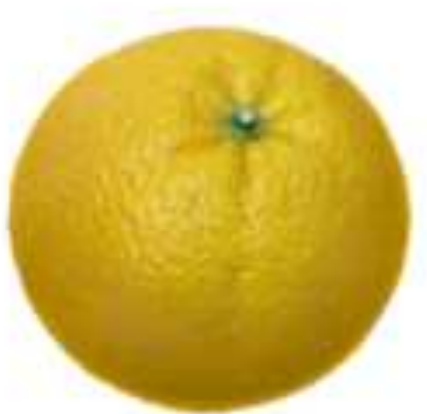

$-10<\mathrm{CCl} \leqslant 0$

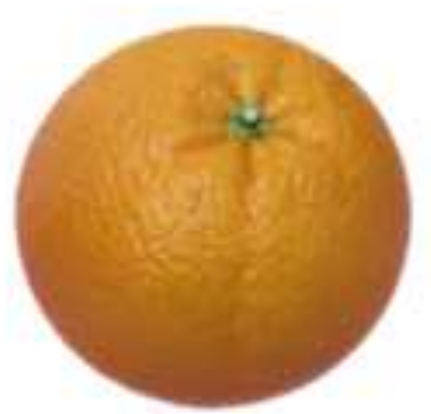

$0<\mathrm{CCl} \leqslant 10$

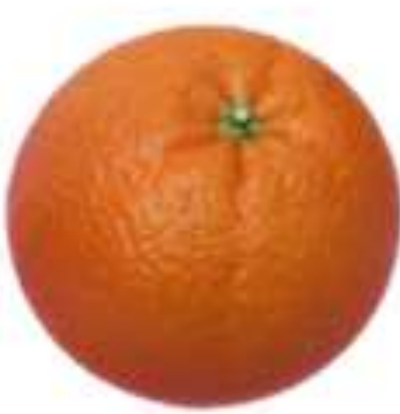

$10<\mathrm{CCl}$ 


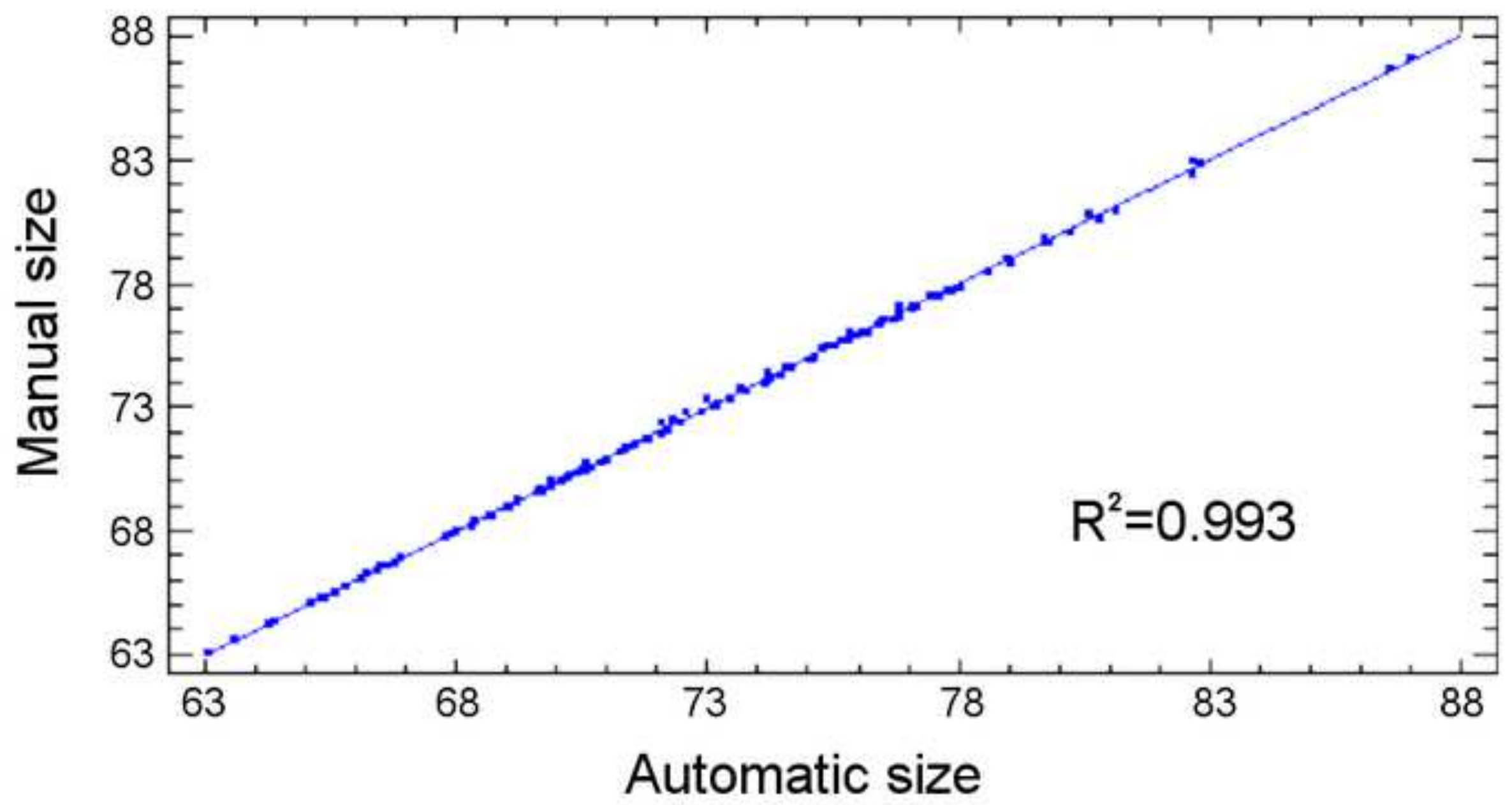




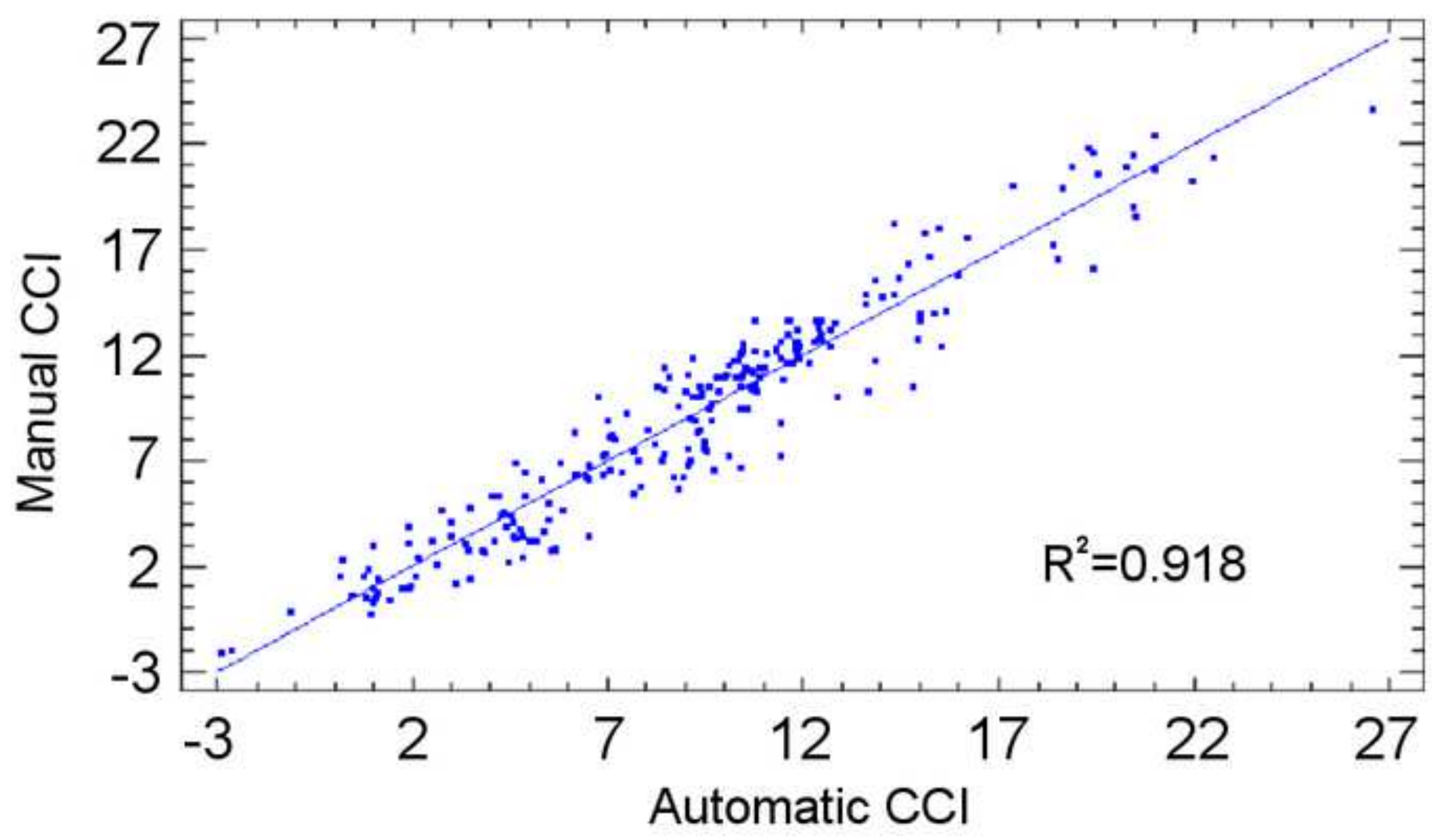




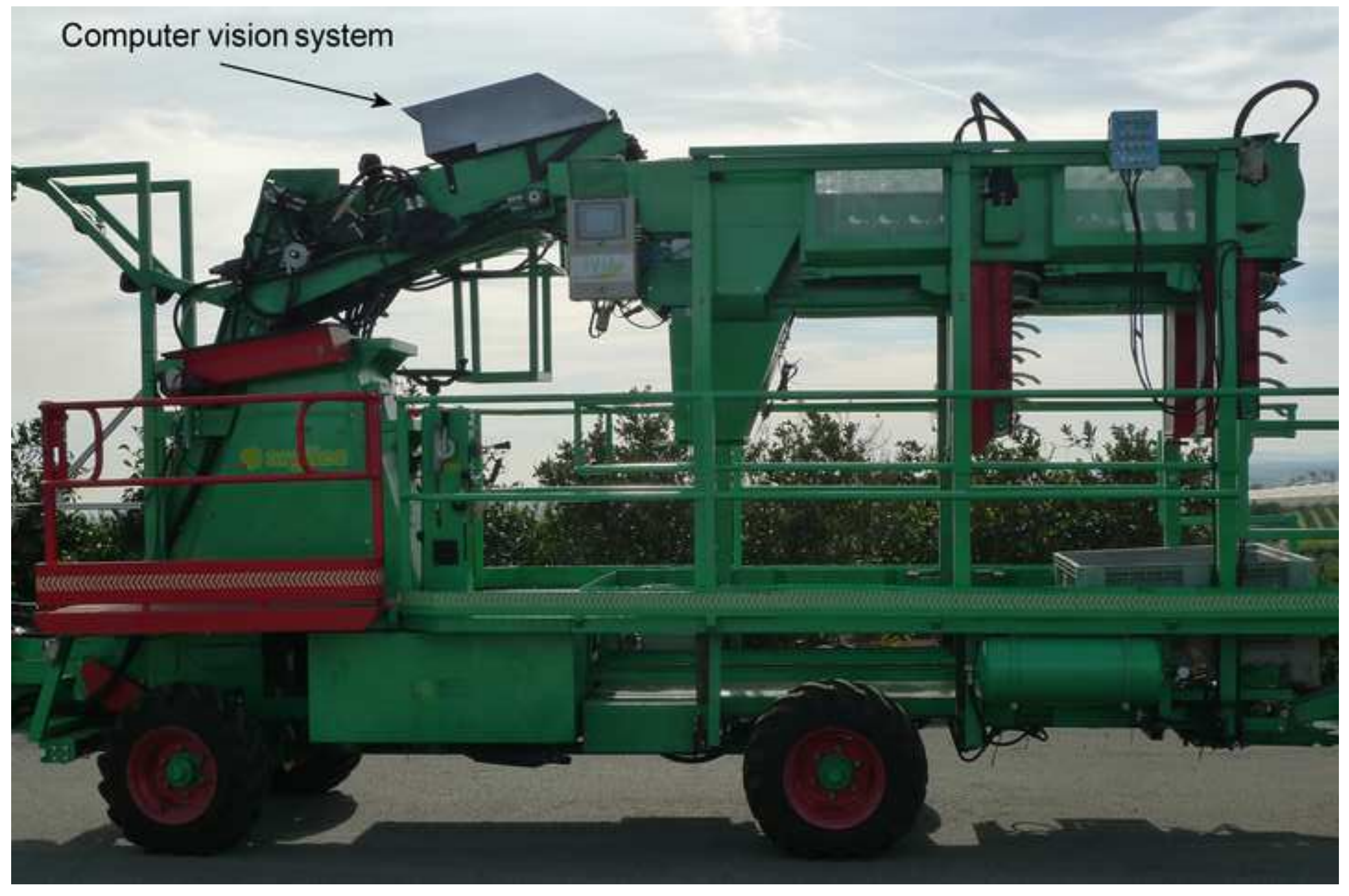

